\title{
PRODUÇÃO VEGETAL DESTINADA AO PROGRAMA DE AQUISIÇÃO DE ALIMENTOS PELOS AGRICULTORES FAMILIARES DE PEREIRA BARRETO - SP: TECNOLOGIAS E ESTRATÉGIAS
}

\author{
Douglas de Araujo Gonzaga ${ }^{1}$ \\ Antonio Lázaro Sant'Ana ${ }^{2}$
}

\begin{abstract}
RESUMO
Na cidade de Pereira Barreto - SP, o Programa de Aquisição de Alimentos (PAA) representa importante política pública tanto pela comercialização dos produtos da agricultura familiar quanto pelo fato de beneficiar diretamente 28 entidades filantrópicas do município. Tendo em vista essas ações, o presente artigo investigou: quais produtos foram entregues; as principais tecnologias empregadas nos sistemas de cultivo e as estratégias de produção dos agricultores familiares participantes do PAA no município. Foram pesquisados, por meio de questionário, 38 produtores participantes do PAA (modalidade Compra com Doação Simultânea), que são moradores de quatro (re)assentamentos rurais do município. Constatou-se grande variedade de produtos de origem vegetal entregues ao PAA e relativa concentração da produção em torno de alguns produtos menos exigentes em infraestrutura e tecnologia. A forma convencional de produção é predominante, porém a maioria dos agricultores adapta seus cultivos às condições de infraestrutura e aos recursos que possuem. Além disso, alguns produtores buscam aliar esses fatores a uma maior autonomia tecnoprodutiva a fim de produzir alimentos mais saudáveis, evitando ou reduzindo o emprego de agroquímicos.
\end{abstract}

Palavras-chave: agricultura familiar, compras públicas, estratégias produtivas, (re)assentamentos rurais.

\section{VEGETABLE PRODUCTION INTENDED FOR THE FOOD ACQUISITION PROGRAM BY FAMILY FARMERS OF PEREIRA BARRETO - SP: TECHNOLOGIES AND STRATEGIES}

\begin{abstract}
In the city of Pereira Barreto (SP) the Programa de Aquisição de Alimentos - PAA (Food Acquisition Program), represents an important public policy, both for the commercialization of family farming products, as the fact that directly benefits 28 philanthropic entities in the city. In view of these actions, the present article examined which products were delivered; the main technologies applied in cropping systems;

\footnotetext{
1 Graduado em Agronomia (FEIS/Unesp). Mestrado em Agronomia (FEIS/Unesp). E-mail: dougsgonzaga@gmail.com

${ }^{2}$ Graduado em Engenharia Agronômica (UnB). Mestrado e Doutorado em Sociologia (FCL/UNESP). LivreDocência em Sociologia (FEIS/UNESP). Prof. adjunto III da Universidade Estadual Paulista "Júlio Mesquita Filho". E-mail: lazaro@agr.feis.unesp.br
} 
and the production strategies developed by family farmers participating in the PAA in the municipality. Were surveyed, through a questionnaire, 38 producers participating in the PAA (mode Purchase with Simultaneous Donation), residents of four rural (re)settlements the city. It showed that there was a great variety of products of plant origin delivered to the PAA and relative concentration of production around some products less demanding for infrastructure and technology. The conventional way of production is predominant, however the majority of the farmers adapt their crops to the conditions of the infrastructure and resources they have. In addition, some farmers seek to combine these factors to a greater autonomy in techno production in order to produce healthier food, avoiding or reducing the use of agrochemicals.

Keywords: family farmers, government purchases, productive strategies, rural settlement.

\section{INTRODUÇÃO}

O Programa de Aquisição de Alimentos (PAA) foi instituído pelo artigo 19 da Lei $n$ ․ 10.696 de 10 de julho de 2003 com o objetivo de promover o acesso à alimentação de pessoas em situação de insegurança alimentar e de incentivar a agricultura familiar. O Programa está inserido na Secretaria Nacional de Segurança Alimentar e Nutricional do Ministério do Desenvolvimento Social (SESAN/MDS), e é uma das ações que compõem o Plano Brasil Sem Miséria (BSM) no eixo da Inclusão Produtiva Rural (BRASIL, 2015).

Pesquisas sobre a execução do PAA têm mostrado o caráter estruturante do Programa, uma vez que propiciou "mudanças em diferentes níveis do processo de produção e nas capacidades organizacionais dos agricultores" (CHMIELEWSKA; LOURETE; SOUZA, 2010, p. 34). Segundo esses pesquisadores, o Programa tem promovido a geração de renda para os agricultores familiares participantes, apoiado na produção de gêneros alimentícios que se enquadram nos hábitos alimentares locais e regionais e, ainda, tem estimulado as formas coletivas de organização. Rocha e Anjos (2013) mencionam, no entanto, que os resultados das políticas públicas voltadas para o desenvolvimento dependem, em grande medida, do capital social das próprias comunidades onde elas estão sendo implementadas.

O Programa é composto por seis modalidades: a) Compra com Doação Simultânea (CDS); b) Apoio à Formação de Estoques pela Agricultura Familiar (CPR Estoque); c) Compra Direta da Agricultura Familiar (CDAF); d) Incentivo à Produção e ao Consumo de Leite (PAA Leite); e) Compras Institucionais e f) Aquisição de Sementes (BRASIL, 2015).

Em suma, o Programa visa combater a fome e a miséria das populações em situação de insegurança alimentar por meio da compra de alimentos produzidos pelos agricultores familiares, sem a necessidade de licitação via mercado institucional. Posteriormente, possibilita realizar a doação dos alimentos para entidades sociais, bem como adquirir produtos da agricultura familiar para a formação de estoques estratégicos (CRUZ et al., 2014).

O PAA em Pereira Barreto (SP) atua na modalidade Compra com Doação Simultânea e é executado via CONAB, sendo que, no período de realização da pesquisa para este artigo (2013-14), beneficiava diretamente 28 entidades filantrópicas tais como: Associação de Pais e Amigos do Excepcional - APAE; Santa Casa de Misericórdia de Pereira Barreto; Grupo Espírita Bezerra de Menezes; 1a Igreja Batista; Centro Espírita Amor e Luz; Creche e Berçário Menino Jesus; Lar dos Idosos - Parque Frederico Ozanan entre outras. Sobre as entidades, nota-se que 
parte delas apresenta cunho religioso. Algumas utilizam os alimentos recebidos e destinam o excedente para as famílias assistidas, ao passo que outras entidades apenas distribuem os alimentos às famílias.

O município de Pereira Barreto está localizado no Noroeste do Estado de São Paulo. É um dos onze munícipios que compõem a Microrregião Geográfica de Andradina e faz parte da Mesorregião Geográfica de Araçatuba. De acordo com o Censo Demográfico de 2010 do Instituto Brasileiro de Geografia e Estatística, a população do município é de 24.962 habitantes, sendo que a população rural totaliza 1.727 pessoas (IBGE, 2016).

Dentre as culturas temporárias desenvolvidas no munícipio, destaca-se a cana-de-açúcar com um total de 26.935 hectares plantados, cuja produção é destinada ao setor sucroalcooleiro. Em relação às demais culturas temporárias, em termos de área plantada, destacam-se: o milho (1000 ha); a soja (885 ha); o amendoim (484 ha); o algodão (242 ha); o tomate (185 ha); a mandioca (68 ha) e o abacaxi (32 ha). As culturas permanentes apresentam menor importância, com um total de apenas 144ha plantados. Dentre elas, a principal é a laranja com 105 ha plantados (IBGE, 2016).

O município está a aproximadamente $140 \mathrm{~km}$ de Araçatuba, sede da Mesorregião, que fica a $190 \mathrm{~km}$ de São José do Rio Preto e a $650 \mathrm{~km}$ de São Paulo (CEAGESP). Os municípios da Mesorregião contam com centrais de abastecimentos e outros entrepostos atacadistas para a comercialização dos alimentos produzidos pelos agricultores.

Nesse contexto, o presente artigo propõe, de modo geral, averiguar quais foram as estratégias adotadas pelos agricultores familiares participantes do PAA em Pereira Barreto para a produção dos alimentos. Para tanto, investigaram-se os seguintes fatores: a) quais produtos foram entregues ao Programa e b) quais foram as principais tecnologias empregadas nos sistemas de cultivo.

\section{METODOLOGIA}

Esta pesquisa adota o conceito de agricultura familiar como a forma de produção e o modo de vida em que o trabalho e a gestão do estabelecimento são predominantemente familiares. Nesse domínio, incluem-se produtores com distintas lógicas produtivas e de reprodução social, bem como diferentes graus de tecnificação e de inserção no mercado (LAMARCHE, 1993; WANDERLEY, 1999).

Para participar do PAA, o produtor deve se enquadrar nos parâmetros da Lei no 11.326 de 24 de julho de 2006, que estabelece as diretrizes para a constituição da Politica Nacional da Agricultura Familiar e Empreendimentos Familiares. Dessa forma, tem-se o marco legal da agricultura familiar, que passa a ter visibilidade nas estatísticas oficiais (DEL GROSSI; MARQUES, 2010). Para que os agricultores se enquadrem nesta lei, é necessário atender quatro requisitos:

I - não detenha, a qualquer título, área maior do que 4 (quatro) módulos fiscais;

II - utilize predominantemente mão-de-obra da própria família nas atividades econômicas do seu estabelecimento ou empreendimento;

III - tenha percentual mínimo da renda familiar originada de atividades econômicas do seu estabelecimento ou empreendimento, na forma definida pelo Poder Executivo; (Redação dada pela Lei oㅜ 12.512, de 2011);

IV - dirija seu estabelecimento ou empreendimento com sua família (BRASIL, 2006). 
A pesquisa de campo consistiu na aplicação de 38 questionários aos agricultores familiares residentes nos assentamentos e no reassentamento de reforma agrária de Pereira Barreto, que participaram do PAA durante o ano de 2012. Na pesquisa, os dados sobre os produtos entregues ao PAA referem-se aos anos de 2012 e 2013, período imediatamente anterior à investigação. E aqui cabe frisar sobre a duração do projeto: embora tenha sido aprovado em meados de 2012, a execução se estendeu até quase o final de 2013.

A seleção dos agricultores entrevistados foi realizada aleatoriamente e abrangeu $40 \%$ do total de produtores efetivamente participantes do PAA no município. Os entrevistados foram: 15 residentes no Assentamento Terra é Vida; 10 do Assentamento Olga Benário; 11 do Assentamento Eldorado dos Carajás e 2 do Reassentamento Complexo Hortifrutigranjeiro.

Os questionários foram aplicados entre os meses de junho de 2013 e fevereiro de 2014, em visitas individualizadas aos estabelecimentos. As informações sobre as associações e os produtores vinculados ao PAA foram fornecidas por profissionais - como, por exemplo, o Engenheiro Agrônomo da Casa da Agricultura e os responsáveis técnicos da Cooperativa de Assistência Técnica e Extensão Rural (COATER) -, que desenvolvem trabalho de assistência técnica e extensão rural no município.

Marconi e Lakatos (2005) salientam que o questionário é um instrumento de coleta de dados, formado por uma série ordenada de perguntas sobre uma situação deliberada. As perguntas abertas possibilitam ao informante responder livremente e emitir opiniões. Já as perguntas fechadas permitem que o informante defina sua resposta de acordo com as opções apresentadas.

Ao elaborar o questionário, buscou-se manifestar os objetivos específicos da pesquisa a partir de itens delimitados e precisos. Conforme aponta Gil (2002), a elaboração do questionário não segue normas rígidas, contudo, deve considerar os seguintes aspectos: o escopo do problema proposto; a clareza e a precisão das perguntas; a possibilidade de uma única interpretação. Do mesmo modo, a elaboração do questionário deve evitar sugerir respostas (postura tendenciosa), ou seja, evitar questões que explorem a intimidade e/ou que deem abertura para respostas defensivas ou socialmente indesejáveis.

Nesse sentido, o questionário foi estruturado com vistas a averiguar as estratégias adotadas pelos agricultores para produzir os alimentos e inserir-se no Programa de Aquisição de Alimentos em Pereira Barreto (SP). Assim, neste artigo, são tratadas as características da produção e as estratégias dos produtores em relação à produção vegetal, cuja finalidade principal é a comercialização via PAA.

\section{RESULTADOS E DISCUSSÃO}

\subsection{CARACTERÍSTICAS GERAIS DOS ASSENTAMENTOS RURAIS}

Todos os assentamentos rurais em que as famílias pesquisadas residem estão localizados no município de Pereira Barreto (SP). Nesta seção, apresentam-se as características gerais de cada um deles.

O Assentamento Rural Terra é Vida foi homologado pelo Instituto Nacional de Colonização e Reforma Agrária (INCRA) em 07/01/2004. Apresenta extensão de 543,4582 ha, divide-se em 39 lotes com área entre 8,90 e 9,97 hectares e localizase a $25 \mathrm{~km}$ do centro urbano. O Assentamento possui também Área de Preservação Permanente (APP) e Reserva Legal (RL). Todos os lotes são cercados em seu perímetro, de modo que alguns têm divisórias internas para melhor alocação das 
atividades agropecuárias. Além disso, também têm energia elétrica e fontes de água potável, originárias da captação em poços semi-artesianos e perfuradas graças aos recursos do INCRA e do Programa Estadual de Microbacias Hidrográficas (CARVALHO, 2013).

Criado em 18/09/2008, o Assentamento Olga Benário tem extensão de 757,5762 hectares e fica a aproximadamente $63 \mathrm{~km}$ do centro urbano de Pereira Barreto. Inicialmente denominado Fazenda Jamaica, o Assentamento beneficiou 49 famílias do Programa Nacional de Reforma Agrária, que receberam áreas de 12 hectares. Todas as famílias aptas já tiveram acesso aos créditos de instalação (Apoio Inicial, Fomento, Adicional do Fomento, Habitação, Apoio Mulher). Ademais, as famílias também acessaram os financiamentos do Programa Nacional de Fortalecimento da Agricultura Familiar (PRONAF) nas modalidades A e A/C. As estradas internas do Assentamento foram abertas graças ao convênio entre o município e o INCRA, sendo o trabalho executado pela Companhia de Desenvolvimento Agrícola de São Paulo (CODASP) (CARVALHO, 2013).

O Assentamento Eldorado dos Carajás foi criado em 08/03/2010. Possui área de 761,0452 ha, com 51 famílias assentadas em lotes de 13 hectares e situa-se a cerca de $68 \mathrm{~km}$ da sede urbana de Pereira Barreto. As famílias deste Assentamento também tiveram acesso aos créditos de instalação (Apoio Inicial, Fomento, Adicional do Fomento, Habitação, Apoio Mulher), bem como aos financiamentos (PRONAF A e, para alguns, o A/C) (CARVALHO, 2013).

Quanto ao Reassentamento Complexo Hortifrutigranjeiro, apesar da escassez de bibliografia, foi possível levantar alguns dados. Criado em 1991, conta com 73 lotes, recobre uma área de 432 hectares e fica a aproximadamente $18 \mathrm{~km}$ do centro urbano de Pereira Barreto. Esse reassentamento abriga antigos proprietários rurais que tiveram suas terras submissas pelo enchimento do lago formado pela barragem da Hidrelétrica de Três Irmãos (HESPANHOL; COSTA; SANTO, 2003).

Gonçalves (2011) estimou que das 70 famílias assentadas originalmente, cerca de 20 apenas permaneciam ainda no Complexo. Outra questão relevante que marca o histórico desse reassentamento é a disputa travada entre a Prefeitura Municipal de Pereira Barreto e a Cesp pela responsabilidade de registros e repasses dos títulos das propriedades aí localizadas.

\subsection{CARACTERÍSTICAS DOS AGRICULTORES FAMILIARES PESQUISADOS}

Os agricultores familiares pesquisados têm características em comum, como, por exemplo, o fato de serem participantes do PAA e beneficiários ${ }^{3}$ de programas públicos de assentamento de reforma agrária. Outras características em comum entre os demais agricultores familiares da região são a baixa escolaridade $(60,6 \%$ não possuem escolaridade ou não concluíram o ensino fundamental) e a origem no campo (84,2\% dos entrevistados tinham ocupações anteriores ligadas à agricultura, embora somente alguns tenham tido experiência anterior no cultivo de olerícolas, principal produto comercializado via PAA). A faixa etária mais frequente é de 40 a 50 anos, sendo que $58 \%$ do total dos pesquisados têm até 50 anos (Tabela 1). Trata-se, portanto, de um grupo pouco mais jovem do que a média de faixa etária constatada em outras pesquisas envolvendo assentados nesta Microrregião.

Silva (2012), ao pesquisar assentamentos da Microrregião de Andradina, apurou que a faixa etária dos agricultores entrevistados era em média de 55 anos,

\footnotetext{
${ }^{3}$ Exceto dois produtores do Reassentamento Hortifrutigranjeiro, que foram instalados pela Companhia Energética de São Paulo (CESP) como medida mitigadora pela construção das hidrelétricas de llha Solteira e Três Irmãos.
} 
sendo que a maior concentração se encontrava na faixa etária de 51 a 60 anos, maior do que aquela verificada por esta pesquisa. Nesse sentido, a autora salientou ainda que cerca de $70 \%$ dos titulares e mais de $50 \%$ dos cônjuges tinham idade superior a 50 anos. De forma análoga Sant'Ana et al. (2007) apurou que 57,5\% dos homens e $66,7 \%$ das mulheres tinham de 40 a 60 anos nos assentamentos dessa mesma Microrregião.

Tabela 1- Faixa etária e escolaridade dos produtores pesquisados

\begin{tabular}{lclc}
\hline \multicolumn{1}{c}{ Faixa Etária } & $\begin{array}{c}\% \text { de } \\
\text { produtores }\end{array}$ & \multicolumn{1}{c}{ Escolaridade } & $\%$ de produtores \\
\hline Até 30 anos & $11 \%$ & Sem Escolaridade & $13,2 \%$ \\
31 a 40 anos & $18 \%$ & Ensino Fundamental Incompleto & $47,4 \%$ \\
41 a 50 anos & $29 \%$ & Ensino Fundamental Completo & $13,2 \%$ \\
51 a 60 anos & $26 \%$ & Ensino Médio Completo & $18,4 \%$ \\
Acima de 60 anos & $16 \%$ & Ensino Técnico Nível Médio & $5,3 \%$ \\
& & Ensino Superior & $2,5 \%$ \\
\hline
\end{tabular}

Fonte: Dados da pesquisa do autor, 2013-2014

O tamanho dos estabelecimentos (lotes) dos produtores pesquisados variou de 9 a 25 hectares. A principal atividade dos agricultores é a pecuária leiteira, mas, em alguns lotes, as olerícolas têm se tornado cada vez mais relevantes e, até mesmo, o cultivo principal, devido à comercialização via PAA e à venda em outros mercados locais.

De modo geral, os agricultores pesquisados não souberam quantificar de forma precisa as áreas destinadas às hortas. Foram observados cultivos com tamanhos e formatos diferentes, sendo que a disposição mais comum foi aquela instalada no entorno da moradia principal. As hortas formadas nos quintais apresentam áreas de até 0,05 hectares (500 metros quadrados). Dentre os entrevistados, apenas os lotes do Reassentamento Complexo Hortifrutigranjeiro dispõem de estruturas para o cultivo protegido de hortaliças.

\subsection{PRODUTOS COMERCIALIZADOS AO PAA}

A Tabela 2 foi construída a partir dos dados disponíveis no Portal Transparência do PAA. Nela, estão as quantidades (em quilos) de cada produto comercializado em 2012 pelas quatro associações a que os agricultores pesquisados estão filiados.

O ano de 2012 foi escolhido para a apresentação dos resultados, pois ano referente a contratos totalmente executados, ou seja, período em que a entrega dos produtos já tinha sido concluída.

A partir dos dados, observa-se que o Assentamento Terra é Vida comercializou a maior quantidade em quilos de hortaliças folhosas, mesmo tendo apresentado uma variedade menor que a dos demais assentamentos. A maior variedade de hortaliças folhosas foi oferecida pelo Assentamento Olga Benário, seguida do Assentamento Eldorado dos Carajás e do Reassentamento Complexo Hortifrutigranjeiro.

Em relação às hortaliças não folhosas, aquele que obteve a maior quantidade de produção foi o Assentamento Terra é Vida, seguido do Assentamento Olga Benário, que, por sua vez, entregou maior variedade de produtos. A maior quantidade (em quilos) de produtos entregues durante o projeto de 2012 refere-se a alimentos desta categoria (hortaliças não folhosas), de modo que o volume total foi de 122.604 quilos, somando onze tipos de vegetais diferentes. 
As raízes e os tubérculos correspondem à terceira categoria de alimentos mais comercializada pelas associações de produtores. Juntas, as associações somam 91.095 quilos de alimentos, que representam as principais fontes de carboidratos e energia para os beneficiários que recebem os alimentos.

Tabela 2 - Relação dos produtos e quantidades (em kg) comercializadas pelas associações pesquisadas do município de Pereira Barreto (SP).

\begin{tabular}{|c|c|c|c|c|c|}
\hline \multirow[b]{2}{*}{ PRODUTOS } & \multicolumn{5}{|c|}{ (RE)ASSENTAMENTOS RURAIS } \\
\hline & $\begin{array}{l}\text { Terra é } \\
\text { Vida }\end{array}$ & $\begin{array}{c}\text { Olga } \\
\text { Benário }\end{array}$ & $\begin{array}{l}\text { Eldora- } \\
\text { do dos } \\
\text { Carajás }\end{array}$ & $\begin{array}{l}\text { Complexo } \\
\text { Horti-fruti }\end{array}$ & TOTAL \\
\hline ABACATE> FORTUNA & & 1.609 & - & - & 1.609 \\
\hline ABÓBORA> (CSC) & 5.300 & 10.857 & 2.242 & 2.242 & 20.641 \\
\hline ABOBRINHA> BRASILEIRA & & 3.521 & - & - & 3.521 \\
\hline ABÓBORA> PAULISTA & 9.070 & & 8.081 & 3.081 & 20.232 \\
\hline ACELGA $>(C S C)$ & - & 4.724 & 650 & 650 & 6.024 \\
\hline ACEROLA> $(C S C)$ & - & 709 & - & - & 709 \\
\hline ALFACE > CRESPA & - & 1.546 & - & - & 1.546 \\
\hline ALFACE $>$ LISA & - & 1.824 & - & - & 1.824 \\
\hline ALFACE $>$ AMERICANA & 11.270 & 1.170 & 6.971 & 2.871 & 22.282 \\
\hline ALMEIRÃO> (CSC) & 12.310 & - & 1.595 & 1.595 & 15.500 \\
\hline ALMEIRÃO> PÃO DE AÇÚCAR & - & 665 & - & - & 665 \\
\hline BANANA> MAÇÃ & 2.100 & & 500 & 500 & 3.100 \\
\hline BANANA $>$ NANICA & - & 1.249 & - & - & 1.249 \\
\hline BATATA> DOCE & 4.100 & 1.899 & 600 & 600 & 7.199 \\
\hline BERINJELA> (CSC) & 3.735 & 3.739 & 2.000 & 2.000 & 11.474 \\
\hline BETERRABA $>(C S C)$ & 2.500 & 2.669 & - & - & 5.169 \\
\hline BRÓCOLIS> (CSC) & - & 2.625 & 500 & 500 & 3.625 \\
\hline CEBOLA> $(C S C)$ & - & - & 500 & 500 & 1.000 \\
\hline CENOURA $>(C S C)$ & 5.860 & 2.728 & 2.800 & 2.800 & 14.188 \\
\hline CHEIRO VERDE> (CSC) & 1.004 & 1.221 & 3.998 & 998 & 7.221 \\
\hline CHICÓRIA> (CSC) & - & - & 750 & 750 & 1.500 \\
\hline CHUCHU> (CSC) & - & 3.259 & - & - & 3.259 \\
\hline COCO> VERDE & 2.525 & 843 & 5.938 & 2.828 & 12.134 \\
\hline COUVE> (CSC) & 1.700 & 5.818 & 2.910 & 2.910 & 13.338 \\
\hline COUVE-FLOR> $(\mathrm{CSC})$ & - & 3.624 & - & - & 3.624 \\
\hline ESCAROLA> $>$ CSC) & - & - & 500 & 500 & 1.000 \\
\hline FEIJÃO> COMUM & - & - & 3.810 & - & 3.810 \\
\hline FEIJÃO> COMUM TIPO 1 E 2 & 4.642 & 1.114 & & 3.810 & 9.566 \\
\hline GOIABA $>$ VERMELHA & & 1.248 & 5.300 & 5.300 & 11.848 \\
\hline JILÓ> REDONDO & 6.251 & 362 & 1.751 & 1.751 & 10.115 \\
\hline LARANJA $>$ PERA & - & 500 & - & - & 500 \\
\hline LIMÃO> TAITI & 600 & 1.645 & - & - & 2.245 \\
\hline MAMÃO> FORMOSA & 500 & 1.084 & - & - & 1.584 \\
\hline MANGA $>$ HADEM & - & 1.084 & - & - & 1.084 \\
\hline MARACUJÁ> AZEDO & 600 & 316 & - & - & 916 \\
\hline MAXIXE> (CSC) & 1.700 & 2.093 & 1.250 & 1.250 & 6.293 \\
\hline MELANCIA> (CSC) & 3.450 & 3.008 & - & - & 6.458 \\
\hline MELÃO> AMARELO & 1.000 & - & - & - & 1.000 \\
\hline MILHO> VERDE EM ESPIGA & 6.800 & 4.178 & - & - & 10.978 \\
\hline PEPINO> COMUM & 4.752 & 3.613 & 6.500 & 500 & 15.365 \\
\hline
\end{tabular}




\begin{tabular}{|c|c|c|c|c|c|}
\hline \multirow[b]{2}{*}{ PRODUTOS } & \multicolumn{5}{|c|}{ (RE)ASSENTAMENTOS RURAIS } \\
\hline & $\begin{array}{c}\text { Terra é } \\
\text { Vida }\end{array}$ & $\begin{array}{c}\text { Olga } \\
\text { Benário }\end{array}$ & $\begin{array}{l}\text { Eldora- } \\
\text { do dos } \\
\text { Carajás }\end{array}$ & $\begin{array}{l}\text { Complexo } \\
\text { Horti-fruti }\end{array}$ & TOTAL \\
\hline PIMENTA > VERDE & 1.100 & - & 600 & 600 & 2.300 \\
\hline PIMENTÃO > VERDE & - & 1.595 & - & - & 1.595 \\
\hline QUIABO> (CSC) & 6.700 & 1.821 & 7.400 & 7.400 & 23.321 \\
\hline RABANETE > (CSC) & 2.850 & 2.930 & 400 & 400 & 6.580 \\
\hline RAIZ DE MANDIOCA> (CSC) & 7.550 & 8.977 & 25.566 & 15.366 & 57.459 \\
\hline REPOLHO> (CSC) & 2.005 & 3.868 & 1.402 & 1.402 & 8.677 \\
\hline RÚCULA $>$ (CSC) & 3.150 & 869 & 3.598 & 598 & 8.215 \\
\hline TANGERINA > PONKAN & 8.645 & 2.842 & - & - & 11.487 \\
\hline TOMATE $>$ (CSC) & 2.800 & 1.688 & - & - & 4.488 \\
\hline VAGEM> FEIJÃO CORADO & 1.620 & - & - & - & 1.620 \\
\hline TOTAL & 128.189 & 101.134 & 98.112 & 63.702 & 391.137 \\
\hline
\end{tabular}

Fonte: (BRASIL, 2014). Organizado pelos autores.

${ }^{*} \mathrm{CSC}$ : classificação sem características

Quanto às frutas, a maior variedade entregue (12) é observada no Assentamento Olga Benário, e a maior quantidade foi comercializada pelo Assentamento Terra é Vida. Já os grãos correspondem à categoria menos comercializada pelos produtores, de modo que o total entregue pelas associações pesquisadas chegou a cerca de 26 toneladas.

De acordo com o Portal Transparência do PAA, as associações a que os produtores entrevistados estão ligados conseguiram comercializar juntas, durante a execução do programa de 2012, um total de $391.137 \mathrm{~kg}$ de alimentos. Naquele ano, o valor montante de produtos comercializados chegou a $\mathrm{R} \$ 465.300$.

\subsection{PRODUTOS COMERCIALIZADOS AO PAA PELOS AGRICULTORES FAMILIARES}

Os agricultores relataram entregar em média nove tipos de produtos durante a execução do PAA ao longo de 2012 e 2013. Uma agricultora chegou a entregar uma variedade de vinte produtos diferentes, enquanto que outro produtor declarou ter ofertado apenas três tipos de alimentos. Os alimentos mais citados foram: abóbora, mandioca, alface e cheiro verde (maços compostos por cebolinha com salsinha e/ou coentro). Para uma análise mais detalhada, dividiram-se os alimentos em cinco categorias: a) hortaliças folhosas; b) hortaliças não folhosas; c) raízes e tubérculos; d) frutas e grãos (Tabela 3 e Tabela 4).

Em relação ao cultivo de hortaliças folhosas e não folhosas, a Tabela 3 contém a relação dos tipos mais frequentes em termos de número e percentual de agricultores que as cultivam. Dentre elas destacam-se: a alface, o cheiro verde, o almeirão, a rúcula e a couve. Já em relação à categoria das hortaliças não folhosas (olerícolas de frutos), os principais produtos são: a abóbora, o quiabo, a berinjela, o jiló e o maxixe.

Em relação às folhosas, é importante salientar que o Assentamento Terra é Vida é o maior fornecedor, o que se deve provavelmente à facilidade maior de transporte de que dispõem em relação aos demais. Além disso, esse Assentamento é um dos mais próximos da cidade, o que pode causar menos danos e estresses nas hortaliças folhosas durante o percurso. Como foi criado há cerca de dez anos, a maioria dos lotes conta com ao menos uma fonte de água potável para consumo e manejo das culturas vegetais e dos animais criados. 
Tabela 3 - Relação de olerícolas entregues ao PAA, em Pereira Barreto, em 201213.

\begin{tabular}{lcc}
\hline Tipos de Hortaliças & № de Agricultores & \% de Agricultores \\
\hline Folhosas & 17 & \\
Alface & 16 & 44,7 \\
Cheiro Verde & 13 & 42,1 \\
Almeirão & 13 & 34,2 \\
Rúcula & 6 & 34,2 \\
Couve & 3 & 15,8 \\
Repolho & 2 & 7,9 \\
Acelga & 4 & 5,3 \\
Outras Folhosas & & 10,5 \\
\hline Não folhosas & 36 & \\
Abóbora & 20 & 94,7 \\
Quiabo & 15 & 52,6 \\
Berinjela & 15 & 39,5 \\
Jiló & 7 & 39,5 \\
Maxixe & 5 & 18,4 \\
Pimenta & 4 & 13,2 \\
Tomate Cereja & 3 & 10,5 \\
Tomate & 10 & 7,9 \\
Outras Hortaliças Não & & 26,3 \\
Folhosas & &
\end{tabular}

Fonte: Dados da pesquisa do autor, 2013-2014.

Os agricultores dos Assentamentos Olga Benário e Eldorado dos Carajás destacaram que produzem uma maior quantidade de hortaliças não folhosas em relação aos outros, pois estão mais distantes do município de Pereira Barreto e, também, porque esses produtos sofrem menos escoriações e danos durante 0 transporte. Já os dois agricultores entrevistados do Reassentamento Complexo Hortifrutigranjeiro não produzem os tipos de olerícolas apresentados pelos demais, não dando destaque para nenhum grupo específico em termos de produção.

A Tabela 4 contém a relação de raízes, tubérculos, frutas e grãos cultivados e entregues ao PAA pelos agricultores entrevistados. O produto de maior destaque é a mandioca, que é cultivada em $89,5 \%$ dos lotes. Devido à grande produção, os agricultores relataram que cada um tem uma cota de entrega semanal de $100 \mathrm{~kg}$.

Como procedimento de entrega, as raízes são lavadas para a retirada do excesso de terra e acondicionadas em caixas plásticas para a pesagem e registro individual. Por outro lado, os produtos que apresentam menor escala são a cenoura, a batata doce, a beterraba e o rabanete.

As frutas também participam do rol de alimentos entregues ao PAA no município de Pereira Barreto. Os agricultores pesquisados citaram 11 tipos de frutas que costumam encaminhar ao Programa. As frutas que apresentam maior frequência são respectivamente: o mamão, a banana, a acerola, o coco verde, o maracujá e a melancia. As demais frutas são comercializadas por um percentual menor de produtores (Tabela 4). 
Tabela 4 - Relação de raízes, tubérculos, frutas e grãos entregues ao PAA em Pereira Barreto (SP) (2012-2013).

\begin{tabular}{lcc}
\hline \multicolumn{1}{c}{ Tipo de Produto } & № DE AGRICULTORES & \% DE AGRICULTORES \\
\hline Raízes e tubérculos & & \\
Mandioca & 34 & 89,5 \\
Cenoura & 7 & 18,4 \\
Batata Doce & 5 & 13,2 \\
Beterraba & 5 & 13,2 \\
Rabanete & 5 & 13,2 \\
\hline Frutas & & \\
Mamão & 10 & 26,3 \\
Banana & 7 & 18,4 \\
Acerola & 6 & 15,8 \\
Coco Verde & 6 & 15,8 \\
Maracujá & 6 & 15,8 \\
Melancia & 5 & 13,2 \\
Limão Taiti & 3 & 7,9 \\
Carambola & 2 & 5,3 \\
Outras Frutas & 3 & 7,9 \\
\hline Grãos & & \\
Feijão Caupi & 22 & 57,9 \\
Milho Verde & 8 & 21,1 \\
Feijão Guandu & 5 & 13,2 \\
Feijão Carioca & 1 & 2,6 \\
\hline nte: Dados da pesquisa do autor, 2013-2014. &
\end{tabular}

Os produtores mencionaram o cultivo de quatro tipos de grãos: feijão caupi ou catador, milho verde, feijão guandu e feijão carioca. Relataram que entregam os feijões caupi e guandu ainda nas vagens, sem nenhum tipo de beneficiamento, apenas com a limpeza e a alocação nas caixas de entrega para posterior pesagem e emissão de recibo de entrega.

De modo geral, observa-se que os dados do Portal Transparência do PAA são coerentes com as informações dos produtores pesquisados, embora pequenas diferenças tenham sido constatadas.

De acordo com as entrevistas com os produtores, 45 diferentes tipos de alimentos foram entregues ao Programa. Entretanto, segundo os dados do Portal Transparência do PAA, as quatro associações de que os produtores entrevistados fazem parte entregaram um total de 50 tipos diferentes de alimentos durante a execução do projeto em 2012. Possivelmente, essa pequena diferença se deve ao fato de que os períodos de referência para o Portal e os agricultores não são exatamente os mesmos. Ademais, notou-se que algumas especificações dos alimentos foram modificadas, como, por exemplo, a referente ao caxi, um alimento regional citado pelos produtores. Esse alimento não foi listado individualmente, e sim incluído junto à soma de abóboras que foram entregues.

\subsection{TECNOLOGIAS E ESTRATÉGIAS PARA A PRODUÇÃO VEGETAL EMPREGADAS PELOS AGRICULTORES FAMILIARES}

As tecnologias adotadas pelos agricultores para a produção dos alimentos que são destinados ao PAA estão listadas na Tabela 5. Para melhor compreensão, as análises foram realizadas por categoria de alimentos: a) hortaliças folhosas; b) hortaliças não folhosas ou de frutos; c) raízes e tubérculos e d) frutas e grãos. $\mathrm{O}$ 
cálculo dos percentuais de utilização das tecnologias e insumos foi realizado com base no total de cada categoria.

Do total de produtores pesquisados, 22 (57,9\%) mencionaram produzir hortaliças folhosas. O preparo do solo mecânico foi a principal tecnologia adotada pelos agricultores para o cultivo desse grupo de hortaliças $(59,1 \%)$. Geralmente, os agricultores contratam esse serviço de forma terceirizada ou, ainda, valem-se das máquinas e implementos agrícolas da associação de agricultores do (re)assentamento ao qual estão vinculados. Os produtores que não utilizam essa opção preparam o solo com o auxílio de tração animal (27,3\%) (Tabela 5). Já os demais empregam instrumentos manuais (enxada e enxadão). Por fim, constatou-se que todos os agricultores fazem os plantios em nível.

No que diz respeito à adubação e à calagem dos canteiros das hortaliças folhosas, temos que $68,2 \%$ dos produtores recorrem às fontes minerais sintéticas para a adubação. Ademais, a adubação orgânica também é observada na produção dos lotes. Os agricultores relataram que essa é a principal fonte nutricional no cultivo das folhosas $(95,5 \%)$. Muitos deles se valem das duas fontes - adubação mineral e orgânica - concomitantemente, de modo que uma complementa a outra.

O uso regular de calcário durante o preparo do solo foi narrado por $36,4 \%$ dos agricultores que possuem folhosas. Mas apenas $13,6 \%$ dos agricultores realizam análise do solo regularmente, a fim de realizar correção do solo e adubação equilibrada dos cultivos (Tabela 5). Esses agricultores se baseiam nas orientações que recebem dos responsáveis técnicos do INCRA, da Casa da Agricultura e, em alguns casos, dos vendedores de lojas agropecuárias.

Em relação às sementes e mudas para a produção de hortaliças folhosas, verifica-se que $100 \%$ dos produtores usam sementes certificadas (Tabela 5). Não foi apurado, contudo, quantos agricultores usam bandejas para a formação de mudas. Entretanto, durante as visitas aos lotes, observou-se que as bandejas estavam presentes na maioria dos produtores de folhosas.

Tabela 5 - Percentual de utilização de tecnologias e insumos

\begin{tabular}{lccccr}
\hline \multicolumn{1}{c}{$\begin{array}{c}\text { Tecnologias } \\
\text { adotadas }\end{array}$} & $\begin{array}{c}\text { Hortaliças } \\
\text { Folhosas }\end{array}$ & $\begin{array}{c}\text { Hortaliças Não } \\
\text { Folhosas }\end{array}$ & $\begin{array}{c}\text { Raízes e } \\
\text { Tubérculos }\end{array}$ & Frutas & Grãos \\
\hline Preparo do solo & & & & & \\
mecânico & $59,1 \%$ & $57,9 \%$ & $91,7 \%$ & $64,3 \%$ & $88,5 \%$ \\
Prep. do solo tração & & & & & \\
animal & $27,3 \%$ & $13,2 \%$ & $16,7 \%$ & $14,3 \%$ & $11,5 \%$ \\
Adubo mineral & $68,2 \%$ & $55,3 \%$ & $52,8 \%$ & $64,3 \%$ & $80,8 \%$ \\
Adubo orgânico & $95,5 \%$ & $55,3 \%$ & $27,8 \%$ & $64,3 \%$ & $46,2 \%$ \\
Calcário & $36,4 \%$ & $18,4 \%$ & $27,8 \%$ & $28,6 \%$ & $26,9 \%$ \\
Irrigação & $40,9 \%$ & $23,7 \%$ & $16,7 \%$ & $14,3 \%$ & $3,8 \%$ \\
Semente Certificada & $95,5 \%$ & $73,7 \%$ & $19,4 \%$ & $46,4 \%$ & $46,2 \%$ \\
Semente Crioula & $0,0 \%$ & $23,7 \%$ & $0,0 \%$ & $71,4 \%$ & $69,2 \%$ \\
Análise de solo & $13,6 \%$ & $10,5 \%$ & $16,7 \%$ & $14,3 \%$ & $19,2 \%$ \\
Herbicidas & $4,5 \%$ & $2,6 \%$ & $2,8 \%$ & $3,6 \%$ & $3,8 \%$ \\
Outros agrotóxicos & $77,3 \%$ & $57,9 \%$ & $33,3 \%$ & $71,4 \%$ & $57,7 \%$ \\
\hline Fotros
\end{tabular}

Fonte: Dados da pesquisa do autor, 2013-2014.

Quanto ao uso de agroquímicos para o controle de pragas, doenças e plantas daninhas, apenas $4,5 \%$ dos agricultores usam herbicidas nos canteiros. Em contrapartida, $77,3 \%$ dos produtores utilizam outros insumos químicos como inseticidas e fungicidas no manejo dessas culturas (Tabela 5). Muitos produtores afirmaram não usar nenhum produto químico sintético, pois preferem utilizar caldas 
e preparados caseiros tais como: solução de água com fumo e sabão neutro; solução de água e sabão; inseticida de neem, calda bordalesa entre outras. Essas aplicações para evitar insetos e fungos são produzidas com produtos naturais a fim de reduzir o uso de agrotóxicos e manter a sanidade das hortaliças.

Dentre os 22 produtores de folhosas, apenas $40,9 \%$ detêm equipamentos de irrigação (Tabela 5), dos quais observou-se o uso de fitas gotejadoras, microaspersores e aspersores. Os agricultores que não possuem esses equipamentos realizam regas constantes com o auxílio de mangueiras e regadores manuais.

Do total de produtores pesquisados, 36 (94,7\%) cultivam hortaliças não folhosas ou frutos. Em relação à caracterização tecnológica da produção das hortaliças não folhosas, observa-se que o principal método de preparo do solo é o mecânico (57,9\%). Apenas $18,4 \%$ dos agricultores realizam calagem antes do plantio. Já a adubação mineral de tipo sintética e orgânica é realizada por pouco mais da metade dos pesquisados (55,3\%) (Tabela 5).

Silva (2012) salienta que os agricultores familiares da mesma microrregião aqui analisada exploram geralmente as olerícolas, pois apresentam baixo custo de produção e não necessitam de tecnologias caras ou infraestrutura específica. Além disso, também são preferidas as culturas que apresentam ciclos curtos de produção, uma vez que geram retornos financeiros relativamente mais rápidos. Uma das olerícolas não folhosas, a abóbora, apresenta várias dessas características, como, por exemplo: a rusticidade, a baixa exigência de tratos culturais, a alta produtividade, e a dupla finalidade (alimentação humana e animal). Dessa forma, verificou-se que a abóbora está presente em quase todos os lotes pesquisados.

Cabe destacar que, embora a maioria utilize sementes certificadas $(73,7 \%)$, $23,7 \%$ dos agricultores usam sementes crioulas para os plantios de algumas das olerícolas descritas nessa categoria (Tabela 5), sobretudo, no cultivo da abóbora, do quiabo e do maxixe. Outros evitam a prática comum de adquirir as mudas já prontas e procedem eles mesmos a formação das mudas de berinjela e do jiló. Com isso, buscam diminuir o custo da produção e garantir maior autonomia em relação à quantidade semeada (uma bandeja de mudas prontas, via de regra, é uma quantidade excessiva para esses produtores).

Os sistemas de irrigação estão presentes em $23,7 \%$ dos lotes que cultivam olerícolas não folhosas. Dos agricultores entrevistados, apenas 10,5\% narraram se valer de análise do solo para programar as adubações das culturas. Em relação aos agrotóxicos utilizados no controle de pragas e doenças dessas culturas, tem-se que $57,9 \%$ dos produtores se valem dessa estratégia, mas apenas $2,6 \%$ usam herbicidas no controle das plantas invasoras (Tabela 5). De modo geral, todos os produtores dessa categoria de olerícolas fazem seus plantios em nível.

É possível observar a presença do cultivo de raízes e tubérculos em 36 $(94,7 \%)$ dos lotes pesquisados. Os agricultores mencionaram com exatidão apenas as áreas dos mandiocais cuja área média por lote é de $0,75 \mathrm{ha}$, sendo que a maior delas é de 2,0 ha, e a menor é de $0,0125 \mathrm{ha}\left(125 \mathrm{~m}^{2}\right)$. Já a área com maior frequência é a de 1,0ha, seguida da de 0,5ha. Como estratégia, os agricultores relataram realizar plantios escalonados a fim de distribuir as colheitas durante 0 ano.

Silva (2012) salienta que a cultura da mandioca na Microrregião de Andradina é uma das principais atividades realizadas pela agricultura familiar em assentamentos rurais. As áreas destinadas aos cultivos da mandioca variam de 0,2ha a 3,6ha; já a produção varia de 0,6 a 50 toneladas/ano. O destino principal da produção, de acordo com a autora, é a fabricação artesanal de farinha, que muitas vezes é realizada no próprio lote. Alguns produtores a comercializam in natura tanto 
no setor varejista quanto na venda direta ao consumidor e aos mercados institucionais.

Quanto às características tecnológicas de produção das olerícolas incluídas no grupo de raízes, o preparo do solo mecânico é o mais usual nessa categoria de olerícolas $(91,7 \%)$. A adoção da calagem pré-plantio só é empregada por $27,8 \%$ dos agricultores, sendo que aqueles que fazem adubação química somam 52,8\%. Por outro lado, a adubação orgânica é realizada por apenas $27,8 \%$ do total dessa categoria. O sistema de irrigação está presente em $16,7 \%$ dos lotes que cultivam raízes e tubérculos. O controle de pragas e doenças nas culturas de raízes e tubérculos é realizado por um terço dos produtores, enquanto que o controle das plantas invasoras com herbicidas quase não é empregado (Tabela 5).

Dentre os produtores pesquisados, $28(73,7 \%)$ possuem algum tipo de fruta em seus lotes. O plantio de frutas foi realizado em áreas que tiveram o preparo do solo mecânico em $64,3 \%$ dos lotes pesquisados. Já o preparo do solo com tração animal ocorreu em $14,3 \%$ dos estabelecimentos. Muitos agricultores realizaram o plantio das mudas frutíferas com auxílio de instrumentos manuais (cavadeira, enxada e enxadão). A adubação orgânica e mineral foi utilizada em $64,3 \%$ dos lotes, sendo que a calagem foi empregada em $28,6 \%$ dos lotes e a análise do solo, que deveria servir de orientação para a correção e adubação, foi feita por apenas $14,3 \%$ dos produtores (Tabela 5).

Os sistemas de irrigação usados no cultivo das frutíferas estão presentes em apenas $14,3 \%$ das propriedades. Os agricultores reportaram utilizar regadores manuais e mangueiras para tentar contornar o déficit hídrico. Já as mudas e as sementes certificadas são utilizadas por menos da metade dos produtores $(46,4 \%)$. O uso de sementes/mudas crioulas é a origem de $71,4 \%$ dos pomares, o que permite constatar que são os próprios agricultores que formam suas mudas e se valem de sementes próprias para realizar os plantios. O emprego dessa estratégia pelos agricultores familiares promove a redução da dependência do uso de insumos externos ao estabelecimento e contribui, em alguns casos, para a preservação de espécies regionais.

Em relação ao uso de agroquímicos no manejo de pragas e doenças das frutíferas, observou-se a utilização desses tipos de agrotóxicos em $71,4 \%$ dos lotes dos produtores de frutas pesquisados. Já os herbicidas foram mencionados por apenas $3,6 \%$ dos pesquisados.

Quanto às tecnologias adotadas no cultivo dos grãos comercializados via PAA, tem-se que, do total de produtores dessa categoria, $22(88,5 \%)$ utilizaram o preparo mecânico do solo para o plantio (Tabela 5). Nas observações de campo, verificou-se que em muitos lotes os plantios são consorciados geralmente com milho e/ou com algumas frutíferas, como o mamão por exemplo.

A adubação mineral predomina nos sistemas de cultivo dos grãos, sendo observada em $80,8 \%$ lotes, enquanto que a adubação orgânica foi constatada em $46,2 \%$ deles. O uso de corretivos (calcário) é adotado por apenas $26,9 \%$ dos lotes. Somente $3,6 \%$ dos estabelecimentos entrevistados mantêm sistemas de irrigação destinados a esses cultivos (Tabela 5).

As sementes certificadas são usadas por menos da metade dos agricultores $(46,2 \%)$, ao passo que a grande maioria $(69,2 \%)$ usa sementes crioulas (Tabela 5 ). Tal fato se explica pelo grande número de produtores de feijão caupi, espécie tradicionalmente cultivada e preservada pelos produtores que mantém um banco de sementes dessa leguminosa para realizar futuros plantios.

O uso de inseticidas e fungicidas (outros agrotóxicos) no controle das pragas e doenças foi verificado em $57,7 \%$ dos lotes. Da mesma forma que nas 
demais categorias de produtos cultivados, apenas um pequeno percentual $(3,8 \%)$ dos produtores controla as plantas invasoras por meio de herbicidas (Tabela 5).

De modo geral, os agricultores pesquisados consideram que as suas atividades agropecuárias, após a adesão dos produtores ao PAA, sofreram alterações. As principais mudanças que os agricultores observaram foram o aumento do número de culturas (42\%) e das áreas plantadas ( $8 \%)$.

A ampliação dos cultivos nos lotes foi apontada por $23(60,5 \%)$ dos 38 agricultores pesquisados. A análise dos dados permitiu verificar que eles passaram a plantar em média sete tipos de vegetais que anteriormente não costumavam cultivar. Os números de aumento de culturas mais citados foram entre seis e oito culturas (ambos com cinco citações). Dois produtores relataram ter implantado mais 10 tipos diferentes de culturas no lote, e um relatou que passou a cultivar outros 15 tipos de alimentos diferentes. Esse mesmo produtor ainda declarou que, caso o Programa não continue, somente diminuirá as áreas e manterá a diversidade dos cultivos, pois assim não precisará mais adquirir esses produtos em supermercados. Esse fato evidencia que a produção também é destinada ao autoconsumo, o que é de extrema importância para esses produtores. No entanto, o fato de a maioria não dispor de sistemas de irrigação faz com que a produção se concentre em torno de alguns produtos menos exigentes no sistema de cultivo.

A diversificação de culturas é uma estratégia típica dos agricultores familiares e o PAA tem sido um instrumento importante para estimular os produtores a retomar este caminho que pode significar maior estabilidade da renda e reforço na segurança alimentar. Isso porque trata-se de uma estratégia que oferece maior disponibilidade de alimentos para o autoconsumo. Efeitos semelhantes também foram observados em outros trabalhos e análises sobre o PAA tais como os de Grisa e Wesz Junior (2010), Dias et al. (2013) e Marques et al. (2014). Deve-se ponderar, no entanto, que a diversificação produtiva não é um resultado uniforme e válido para todos os locais, pois no município de Junqueirópolis (SP), Veloso e Hespanhol (2012) constataram que o PAA contribuiu para reforçar a especialização produtiva, ou seja, para fortalecer a produção de apenas um tipo de alimento.

A maioria dos produtores mantem parte dos cultivos na forma convencional, baseado no uso de insumos externos aos estabelecimentos rurais (adubos sintéticos, inseticidas, fungicidas e sementes certificadas). Apesar disso, muitos almejam introduzir práticas alternativas e métodos da agricultura de base ecológica como a preparação de caldas e outras estratégias para o controle de algumas pragas e doenças. No caso de alguns alimentos como a alface, por exemplo, parte dos produtores não aplica nenhum agrotóxico, uma vez que se preocupam com os efeitos residuais desses produtos.

Como estratégia para os cultivos, os agricultores procuram reservar parte dos recursos que recebem como o pagamento da entrega dos produtos ao PAA. Com isso, visam o pagamento da hora/máquina e/ou óleo diesel para o preparo do solo com os tratores da associação a que estão vinculados. De modo geral, os produtores planejam quais áreas serão aradas para os futuros plantios e para a implantação da horta. Planejam ainda as quadras (talhões com área correspondente a um quarto de alqueire ou de aproximadamente 0,6 hectare) para a implantação de mandiocais e plantios de abóbora.

As principais dificuldades citadas pelos agricultores em relação aos cultivos foram: a falta de água (devido à seca mais severa que acometeu a região e o estado de São Paulo nos últimos meses de entrega dos alimentos em 2013) e a falta de energia elétrica (essa dificuldade é citada apenas pelo Assentamento Eldorado dos Carajás que foi contemplado com o Programa Luz para Todos somente no segundo semestre de 2014). 
Durante a aplicação dos questionários, observou-se que o predomínio de cultivos de alface, abóbora, feijão caupi, quiabo, mamão e mandioca deve-se ao fato de que essas culturas não dependem de alto nível tecnológico e exigem poucos tratos culturais (a alface é exigente em mão-de-obra, entretanto, possui alta demanda).

A infraestrutura dos lotes entrevistados do Complexo Hortifrutigranjeiro é mais completa no que concerne à presença de cultivos protegidos (áreas cercadas com telados de polipropileno). Já nos assentamentos não foi observado esse tipo de estrutura. Algumas hortas são cercadas com telas a fim de impedir o acesso de galinhas, lebrões e, até mesmo, antas.

Algumas famílias ainda não estão consolidadas nas atividades agrícolas. Muitas delas narraram nunca terem trabalhado antes com o cultivo de hortaliças em geral, somente com grãos. Nesse aspecto, cabe ressaltar que apenas ao adquirir essa experiência os agricultores terão plenas condições de se estabelecer e elaborar estratégias mais consistentes diante das adversidades dessas atividades agrícolas.

\section{CONSIDERAÇÕES FINAIS}

Com base nos resultados obtidos, pode-se observar uma grande variedade de alimentos produzidos e entregues ao Programa de Aquisição de Alimentos pelos agricultores familiares entrevistados. Nesse sentido, constatou-se que a diversidade foi resultado direto da participação no referido Programa. No entanto, em termos de quantidade produzida e entregue, constatou-se certa concentração da produção em torno de alguns produtos. Essa ação se deve ao fato de que não são produtos tão exigentes em termos tecnológicos e, ainda, às limitações dos agricultores em termos de infraestrutura (especialmente irrigação) e de conhecimento na área de olericultura.

Quanto às estratégias e tecnologias de produção, verificou-se que a maioria dos produtores pesquisados segue o padrão produtivo convencional, isto é, faz uso de insumos fertilizantes sintéticos, agrotóxicos e sementes certificadas. Além disso, a maioria dos produtores orienta a escolha de quais alimentos serão produzidos conforme os conhecimentos que possuem. Outro aspecto relevante verificado pela pesquisa refere-se à adaptação de seus sistemas de cultivos às restrições de infraestrutura e de recursos que enfrentam. Por fim, alguns relataram ter outros objetivos no Programa como, por exemplo, a busca por maior autonomia tecnoprodutiva e o desejo de produzir alimentos mais saudáveis para evitar ou reduzir o uso agroquímicos.

\section{REFERÊNCIAS}

BRASIL. Lei n. 11.326 de 24 de julho de 2006 Estabelece as diretrizes para a formulação da Política Nacional da Agricultura Familiar e Empreendimentos Familiares Rurais. Diário Oficial [da] República Federativa do Brasil, 25 jul. 2006. Disponível em: <http://www.planalto.gov.br/ccivil_03/_ato20042006/2006/lei/l11326.htm>. Acesso em: 28 mai. 2016.

BRASIL. Ministério da Agricultura, Pecuária e Abastecimento. CONAB. Companhia Nacional de Abastecimento, 2014. Disponível em: <www.conab.gov.br/> Acesso em: 9 fev. 2015. 
BRASIL. Ministério do Desenvolvimento Social e Combate à Fome. Secretaria Nacional de Segurança Alimentar e Nutricional. Programa de Aquisição de Alimentos - $2015 . \quad$ PAA. Disponível em: <http://www.mds.gov.br/segurancaalimentar/aquisicao-e-comercializacao-daagricultura-familiar>. Acesso em: 9 fev. 2015.

CHMIELEWSKA, D.; LOURETE, A. A.; SOUZA, D. O programa de aquisição de alimentos da agricultura familiar (PAA) e as práticas dos agricultores participantes orientadas ao mercado: estudo de caso no Estado de Sergipe. Brasília: set. 2010. (Texto para discussão, n. 1510). Disponível em: <http://www.ipea.gov.br/agencia/images/stories/PDFs/TDs/td_1510.pdf>. Acesso em: jan. 2015.

CRUZ, K. C. M. S.; et al. $\mathbf{O}$ acesso da agricultura familiar brasileira às políticas públicas: a evolução do Programa de Aquisição de Alimentos. 2014. CONAB. Disponível em: <http://www.conab.gov.br/OlalaCMS/uploads/arquivos/14_09_15_16_03_05_artigo_ evolucao_do_paa_2.pdf>. Acesso em: 19 nov. 2014.

DEL GROSSI, M. E.; MARQUES, V. P. M. A.; Agricultura familiar no censo agropecuário 2006: o marco legal e as opções para sua identificação. Estudos Sociedade e Agricultura. Rio de Janeiro, vol. 18, n. 1, 2010: 127-157. Disponível em: < http://r1.ufrrj.br/esa/V2/ojs/index.php/esa/article/view/322/318>. Acesso em: 28 mai. 2016.

DIAS, T. F.; et al. O Programa de Aquisição de Alimentos da Agricultura Familiar (PAA) como estratégia de inserção socioeconômica: o caso do Território da Cidadania Sertão do Apodi (RN). Gestão \& Desenvolvimento Regional, Taubaté, v. 9 , n. 3, p. 100-129, set-dez. 2013.

GIL, A. C. Como elaborar projetos de pesquisa. 4ª Ed. São Paulo: Atlas, 2002.

GONÇALVES, J. C. Conflitos socioambientais da construção e da operação de UHEs no município de Pereira Barreto/SP. In: CONGRESSO INTERNACIONAL DA ALAS, n. 28, 2011. UFPE, Recife, PE. Anais... Disponível em: $<\mathrm{http}: / /$ www.ufscar.br/neped/pdfs/anais/ALAS_2011-J.C._Goncalves.pdf>. Acesso em: jan. 2015.

GRISA, C.; WESZ JUNIOR, V. J. Políticas públicas para a agricultura familiar: entre avanços e desafios. Carta Maior, São Paulo/SP, 29 set. 2010.

IBGE. Instituto Brasileiro de Geografia e Estatística. Cidades@. Disponível em:<http://www.cidades.ibge.gov.br/xtras/perfil.php?lang=\&codmun=353740\&search =sao-paulo|pereira-barreto $>$. Acesso em: 28 mai. 2016 .

LAMARCHE, H. (Coord.) A agricultura familiar: uma realidade multiforme. Campinas: Ed. da UNICAMP, v. 1, 1993, p. 336.

MARCONI, M. A.; LAKATOS, E. M. Fundamentos de metodologia científica. 6. ed. São Paulo: Atlas, 2005. p. 315. 
MARQUES, P. E. M.; et al. Programa de Aquisição de Alimentos (PAA) no Estado de São Paulo: agricultura de proximidade em questão. Ruris, Campinas, v. 8, n. 1, p. 63-89, mar. 2014.

ROCHA, J. H.; ANJOS, F. S. A sociologia econômica e os mercados protegidos: um arcabouço teórico e analítico para o Programa de Aquisição de Alimentos. Extensão Rural, Santa Maria, v. 20, n. 2, p. 30-61, mai./ago. 2013.

SANT'ANA, A. L.; et al. Estratégias de produção e comercialização dos assentados da região de Andradina - SP. Informações Econômicas, São Paulo, v. 37, n. 5, p. 29-31, maio 2007.

SILVA, F. C. Agricultura familiar em duas microrregiões do noroeste do estado de São Paulo: Uma análise comparativa entre as explorações agropecuárias e as políticas públicas dirigidas ao segmento. 2012. 137 f. Dissertação (Mestrado em Agronomia) - Faculdade de Engenharia de Ilha Solteira, Universidade Estadual Paulista "Júlio de Mesquita Filho", Ilha Solteira, 2012.

VELOSO, F. HESPANHOL, R. A. M. O PAA na região de Dracena: da diversificação à especialização produtiva. Caderno Prudentino de Geografia, Presidente Prudente, n. 34, v. 1, p. 161-178, jan./jul. 2012.

WANDERLEY, M. N. B. Raízes históricas do campesinato brasileiro. In: TEDESCO, J. C. (Org.) Agricultura familiar: realidades e perspectivas. P. Fundo: EDIUPF, 1999. p. 23-56. 